\title{
miR-211-5p inhibits the proliferation, migration, invasion, and induces apoptosis of human hypertrophic scar fibroblasts by regulating TGF $\beta R 2$ expression
}

\author{
Jun Tang ${ }^{1 *}$, Jianing Yang ${ }^{2,3 *}$, Hua $\mathrm{Hu}^{1}$, Ying $\mathrm{Cen}^{1 *}$, Junjie Chen ${ }^{1 *}$ \\ ${ }^{1}$ Department of Plastic and Burn Surgery, West China Hospital, Sichuan University, Chengdu, China; ${ }^{2}$ Department of Dermatology, Sichuan \\ Provincial People's Hospital, Chengdu, China; ${ }^{3}$ Chinese Academy of Sciences Sichuan Translational Medicine Research Hospital, Chengdu, China \\ Contributions: (I) Conception and design: J Tang, Y Cen, J Chen; (II) Administrative support: J Yang, H Hu; (III) Provision of study materials \\ or patients: J Tang, Y Cen, J Chen; (IV) Collection and assembly of data: All authors; (V) Data analysis and interpretation: J Tang, J Chen; (VI) \\ Manuscript writing: All authors; (VII) Final approval of manuscript: All authors. \\ "These authors contributed equally to this work. \\ *These authors contributed equally to this work. \\ Correspondence to: Ying Cen; Junjie Chen. Department of Plastic and Burn Surgery, West China Hospital, Sichuan University, Guoxue Xiang, \\ Chengdu 610041, China. Email: hx_cenying@163.com; cjjemail@163.com.
}

Background: Hypertrophic-scar (HS) is the most common pathological healing phenomenon after trauma, especially after deep burns. We aimed to investigate the expression and role of microRNA-211-5p (miR-211-5p) in HS and explore its underlying mechanism.

Methods: Quantitative real-time polymerase chain reaction (qRT-PCR) was used to detect the expression of miR-211-5p in 15 cases of HS tissues and normal skin tissues, as well as its expression in human hypertrophic scar fibroblasts (hHSFs) and normal fibroblasts. At the same time, the cell counting kit-8 (CCK-8), scratch test, cell invasion test, and flow cytometry were used to determine cell proliferation, migration, invasion, and apoptosis, respectively. Western blot assay was used to determine the expression of proteins. TargetScan was performed to predict the potential binding sites between miR-211-5p and TGFßR2, which was then verified by western blotting and luciferase reporter gene experiments. Also, co-transfection of plasmids that overexpress miR-211-5p and TGF $\beta$ R2 were used to observe the reversal effect of miR-211-5p.

Results: The level of miR-211-5p in HS tissues and hHSFs cells was significantly down-regulated (both $\mathrm{P}<0.05$ ). The TGF $\beta$ R2/Smad3 signaling pathway was activated (both $\mathrm{P}<0.05$ ). Furthermore, the overexpression of miR-211-5p could inhibit the proliferation $(\mathrm{P}<0.05)$, migration $(\mathrm{P}<0.05)$, and invasion $(\mathrm{P}<0.05)$ of hHSFs cells, and induce their apoptosis $(\mathrm{P}<0.05)$, and could also regulate the expression of related proteins (all $\mathrm{P}<0.05$ ). Moreover, the overexpression of miR-211-5p could also inhibit the accumulation of ECM and the activation of the TGF- $\beta$ R2/Smad3 pathway (all $\mathrm{P}<0.05$ ), while the opposite effect (all $\mathrm{P}<0.05$ ) was observed when the level of miR-211-5p was interfered with. Finally, it was confirmed that miR-211-5p could target TGF $\beta$ R2 (all $\mathrm{P}<0.05$ ), and when hHSFs cells simultaneously overexpressed miR-211-5p and TGF $\beta R 2$, the promotion effect of TGF $\beta 22$ on cells was reversed by miR-211-5p (all $\mathrm{P}<0.05)$.

Conclusions: miR-211-5p can inhibit the activation of the TGF- $\beta$ R $2 / \operatorname{Smad} 3$ signaling pathway by targeting TGF $\beta$ R2, thereby suppressing the proliferation, migration, invasion, and ECM production of hHSFs, and inducing their apoptosis, suggesting that miR-211-5p can become a potential target for the treatment of HS.

Keywords: miR-211-5p; hypertrophic scar (HS); fibroblasts; proliferation; apoptosis; TGF $\beta$ R2

Submitted Mar 24, 2021. Accepted for publication May 13, 2021.

doi: $10.21037 /$ atm-21-1806

View this article at: http://dx.doi.org/10.21037/atm-21-1806 


\section{Introduction}

Hypertrophic scar (HS) is a common disease caused by abnormal skin tissue repair after burns or surgical trauma (1). It is characterized by abnormally increased activity of numerous cells (such as fibroblasts), excessive proliferation of cells, and increased collagen deposition (2). The reduced elasticity of scar tissue destroys the normal anatomical structure of the skin tissue on the body surface, thereby affecting the appearance of the skin, and leading to varying degrees of tissue and organ dysfunction. This negatively impacts the normal life and work of the patient, injures their body, and affects their positive mentality $(3,4)$. At present, the treatment for HS mainly includes comprehensive therapies such as surgery, silica gel, radiotherapy, cryotherapy, and compression therapy, however there is no particularly effective treatment method (5). Abnormal proliferation and activation of fibroblasts are considered to be the main feature of HS (2). However, the pathogenesis of HS requires further study, which is a huge challenge for clinical treatment (6). In recent years, researchers have conducted numerous in-depth studies on the underlying mechanisms associated with the pathogenesis of HS. It has been shown that the prevention and treatment of HS should avoid or reduce the occurrence and development of abnormal scars at the source. Identifying the genetic defects of HS and correcting them at the genetic level is the premise for the breakthrough treatment of the HS (7-9).

MicroRNAs (miRNAs) can recognize and bind related target genes in a completely or incompletely complementary fashion (10), and cut or inhibit the translation of the target gene, which regulates the expression of genes and/ or proteins after transcription $(11,12)$. Studies have shown that miRNAs can play a vital role in the occurrence and development of HS through a variety of mechanisms (13-15). According to previous studies, miR-211-5p is a pro-survival miRNA (16), but also a pro-apoptotic miRNA (17). MiR211-5p is decreased in osteosarcoma, could regulate cell functions (18). Similarly, miR-211-5p is also decreased in breast cancer tissues, and its overexpression could suppress the development of breast cancer (19). Shang et al. found that miR-211-5p can reduce ischemia/reperfusion-induced kidney injury by regulating the activation of TGF $\beta$ R2/ TGF- $\beta /$ Smad 3 pathway (20). Nonetheless, the roles of miR-211-5p in the occurrence and development of HS are still unclear.

Therefore, in this study, we aim to investigate the expression of miR-211-5p in HS tissues and human HS fibroblasts (hHSFs), and to further elucidate the roles of miR-211-5p in hHSFs and explore its underlying mechanism.

We present the following article in accordance with the MDAR reporting checklist (available at http://dx.doi. org/10.21037/atm-21-1806).

\section{Methods}

\section{Clinical sample collection}

Fifteen HS tissues and 15 normal skin tissue samples from patients undergoing scar resection and repair surgery in our hospital from January to October 2020 were collected. The clinical tissue samples in this study were only used for research purposes. All participants had signed the informed consent form before participating in the study. All procedures performed in this study involving human participants were in accordance with the Declaration of Helsinki (as revised in 2013). The study was approved by the Ethics Committee of West China Hospital, Sichuan University (No.: ChiCTR1800019082).

\section{Cell culture}

Briefly, HS tissues were rinsed with phosphate-buffered saline (PBS), and Dulbecco's modified Eagle's medium (DMEM; Gibco, USA) containing $0.1 \%$ type I collagenase (Sigma, USA) was used to incubate the minced tissue at $37^{\circ} \mathrm{C}$ for $3 \mathrm{~h}$. Next, the hHSFs were cultured in DMEM medium containing $10 \%$ fetal bovine serum (FBS, Gibco), $1 \%$ penicillin, and $1 \%$ streptomycin double antibiotics (Invitrogen, USA) at $37{ }^{\circ} \mathrm{C}$ in a humidified atmosphere with $5 \% \mathrm{CO}_{2}$. In this study, third to fifth generations of hHSFs that reached $70-80 \%$ confluence were used for subsequent experiments.

\section{$R N A$ extraction and real-time fluorescent quantitative polymerase chain reaction ( $q R T-P C R$ )}

The cellular RNA was extracted with TRIzol reagent (Takara, Japan) strictly according to the manufacturer's instructions. The miScript reverse transcription kit (Qiagen, German) was used to synthesize the cDNA for the detection of miRNA, and PrimeScript ${ }^{\mathrm{TM}}$ Reverse Transcription Kit (TaKaRa, Japan) was used to synthesize the cDNA for mRNA detection. The SYBR Green PCR kit (TaKaRa, Japan) was used for specific amplification of cDNA on the ABI7500 real-time PCR system (Applied Biosystems, USA). U6 and GAPDH were used as the internal loading controls 
Table 1 Primer sequences of target genes

\begin{tabular}{lll}
\hline Target gene & Forward primer $\left(3^{\prime}-5^{\prime}\right)$ & Reverse primer $\left(3^{\prime}-5^{\prime}\right)$ \\
\hline miR-211-5p & CCGGAATTCCGGTTTACAACACCCCATTTCACC & CGCGGATCCGCGCGAGCAACAGAGTAGAACAGG \\
U6 & GCTTCGGCAGCACATATACTAAAAT & CGCTTCACGAATTTGGTGTCAT \\
TGF $\beta R 2$ & GTAGCTCTGATGAGTGCAATGAC & CAGATATGGCAACTCCCAGTG \\
GAPDH & CTTTGGTATCGTGGAAGGACTC & GTAGAGGCAGGGATGATGTTCT \\
\hline
\end{tabular}

TGFGAG, transforming growth factor receptor 2 .

for miRNA and mRNA, respectively. The $2^{-\Delta \Delta C t}$ method was used to determine the relative quantification of genes. Primer sequences are shown in Table 1.

\section{Cell transfection}

Plasmids of miR-211-5p mimic (mimic), inhibitor (inhibitor), and negative control (NC), as well as the plasmids that overexpressed the transforming growth factor $\beta$ receptor 2 (TGF $\beta \mathrm{R} 2$ ) and its control (Vector), were all synthesized by Shanghai Jima Pharmaceutical Technology Co., Ltd. (China). Lipofectamine 2000 (Invitrogen, USA) was used for cell transfections according to the manufacturer's instructions.

\section{Cell proliferation measurement}

Cell proliferation was determined using the cell counting kit-8 (CCK-8, Dojindo, Japan). First, cells transfected with the miR-211-5p mimic, inhibitor, NC, or TGF $\beta$ R2, Vector for $48 \mathrm{~h}$ were seeded into 96 -well plates $\left(1 \times 10^{4}\right.$ cells/well). After $0,12,24,36$, and $48 \mathrm{~h}, 10 \mu \mathrm{L}$ of CCK- 8 were added to each well. After continuous culturing for $2 \mathrm{~h}$ at $37^{\circ} \mathrm{C}$, the absorbance at $450 \mathrm{~nm}$ was detected with a spectrophotometer (BioTek Instruments, USA).

\section{Caspase-3 activity determination}

Caspase-3 activity detection kit (Biyuntian Biotechnology Co., Ltd., China) was used to detect cell apoptosis. Briefly, the lysed cells were incubated with $2 \mathrm{mM}$ Ac DEVD pNA in the reaction buffer at $37^{\circ} \mathrm{C}$ for $2 \mathrm{~h}$. Subsequently, a spectrophotometer was used to detect the absorbance value at $405 \mathrm{~nm}$.

\section{Flow cytometry to measure cell apoptosis}

hHSFs cells were first digested with trypsin and resuspended in PBS, and the Annexin V-FITC Kit (Invitrogen, USA) was then used to measure apoptosis strictly according to the manufacturer's instructions. Specifically, $48 \mathrm{~h}$ after transfection of the miR-211-5p mimic, inhibitor, and NC, the hHSFs were treated with $0.25 \%$ trypsin without EDTA. The cells were then washed twice with pre-chilled PBS and resuspended in the binding buffer. Annexin V-FITC and PI were then added to the cell suspension for a $15-\mathrm{min}$ incubation at room temperature in the dark. Flow cytometry (FACS Calibur, BD Bioscience, USA) was then used to determine the apoptosis of the samples, and the Flowjo software (Treestar, Inc., USA) was used to analyze the apoptosis rate of each group of cells.

\section{Dual luciferase experiment}

The 3'-untranslated region (UTR) fragments of wild type (WT) or mutant type (MUT) TGFßR2 containing the predicted miR-211-5p targeting sites was cloned into the dual luciferase miRNA target expression vector pmirGLO vector (Promega, USA). The constructed vector and miR211-5p mimic or inhibitor were then transfected into the hHSFs. The transfected hHSFs were cultured at $37^{\circ} \mathrm{C}$ for $48 \mathrm{~h}$, and the luciferase activity of the cells was then analyzed with the dual-luciferase reporter analysis system (Promega, USA).

\section{Scratch test}

The stably-transfected hHSFs $\left(3 \times 10^{5}\right.$ cells/well $)$ were inoculated into a six-well plate. When the cells reached contact inhibition, a $10-\mu \mathrm{L}$ pipette tip was used to vertically draw three parallel lines on the plate. The exfoliated cells were rinsed off with PBS, and were then cultured in a serum-free medium. The scratches were observed, photographed, and recorded under a microscope (Olympus, Japan) at 0 and $48 \mathrm{~h}$. The migration distance based on the scratch area of the cell at 0 and $48 \mathrm{~h}$ was then calculated. 


\section{Cell invasion test}

The transwell plate chamber (3428, Corning, USA) was pretreated with matrigel glue (Corning, USA) at $4 \mathrm{~h}$, and placed overnight at $37^{\circ} \mathrm{C}$. A number of $2 \times 10^{3}$ cells/well was then seeded in the upper chamber of the transwell chamber containing serum-free medium, and $600 \mu \mathrm{L}$ of normal medium containing $10 \%$ FBS was added to the lower chamber. After $24 \mathrm{~h}$ of incubation, the liquid was discarded, and the cells were fixed with $4 \%$ methanol (Biyuntian Biotechnology Co., Ltd., China) at room temperature for 15 min. After staining with $0.1 \%$ crystal violet (Biyuntian Biotechnology Co., Ltd., China) at room temperature for $20 \mathrm{~min}$, the number of cells was counted from 10 randomly chosen areas under a microscope.

\section{Detection of protein expression level with western blot}

The cells were lysed with a strong RIPA lysis solution (Biyuntian Biotechnology Co., Ltd., China), and then the protein concentration of the sample was determined using the BCA kit (Biyuntian Biotechnology Co., Ltd., China) according to the manufacturer's instructions. A total of $40 \mu \mathrm{g}$ of protein extract from each sample was separated on a $10 \%$ SDS-PAGE gel and then transferred to a PVDF membrane (Millipore, USA), which was then blocked with $5 \%$ skim milk at $37^{\circ} \mathrm{C}$ for $1 \mathrm{~h}$, and then incubated with primary antibody overnight at $4{ }^{\circ} \mathrm{C}$. Primary antibodies included transforming growth factor receptor 2 (TGFßR2, ab184948, abcam, UK), G1/S-specific cyclin-D1 (CCND1, ab16663, abcam, UK), C-myc (ab32072, abcam, UK), Bcl2Associated X (Bax, ab32503), B-cell lymphoma-2(Bcl-2, ab182858, abcam, UK), matrix metalloproteinase 3 (MMP3, ab52915, abcam, UK), matrix metalloproteinase 9 (MMP9, ab76003, abcam, UK), $\alpha$-smooth muscle actin ( $\alpha$-SMA, ab5831, abcam, UK), type 1 collagen (Col I, ab34710, abcam, UK), Col III (ab184993, abcam, UK), Smad3 (ab40854, abcam, UK), phosphorylated Smad3 (ab52903, abcam, UK), and GAPDH (ab8245, abcam, UK). The next day, the membrane was incubated with the appropriate secondary antibody (Sigma, USA) for $1 \mathrm{~h}$ at room temperature. Electrochemi-luminescence (ECL) Kit (Thermo Fisher Scientific, USA) was used to observe protein bands in the imaging system, and the relative protein expression level of cells was analyzed according to the gray value.

\section{Statistical analysis}

The data were represented as mean \pm standard deviation, and SPSS19.0 statistical software (SPSS, USA) was used for data analysis. The difference between different groups was compared with the $t$-test, and one-way analysis of variance was used to compare groups under the same conditions. The difference was statistically significant when $\mathrm{P}<0.05$.

\section{Results}

\section{The level of miR-211-5p was reduced in HS tissues and bHSFs}

This study firstly used qRT-PCR to determine the level of miR-211-5p in HS tissues. As shown in Figure 1A, the expression level of miR-211-5p in HS tissue was significantly reduced $(\mathrm{P}<0.05)$ compared to the normal control. Moreover, as shown in Figure $1 B$, this study also found that the expression level of miR-211-5p in fibroblasts derived from HS was also significantly lower than that in fibroblasts derived from normal skin $(\mathrm{P}<0.05)$. In addition, this study also detected the activation of TGF $\beta R 2$ and Smad3 proteins in human normal and HS tissues, as well as normal skin and HS fibroblasts. As shown in Figure $1 C$ and D, this study found that HS tissues and TGF $\beta$ R2 levels in cells significantly increased compared with normal tissues and normal cells $(\mathrm{P}<0.05)$. In addition, the phosphorylation level of Smad3 also increased significantly $(\mathrm{P}<0.05)$.

\section{miR-211-5p inbibited cell functions and induced apoptosis in bHSFs}

As shown in Figure 2A, this study first verified the effectiveness of the miR-211-5p mimic and inhibitor (both $\mathrm{P}<0.05)$. The CCK-8 method was then used to determine the effect of miR-211-5p on cell proliferation. The overexpression of miR-211-5p in hHSFs cells significantly inhibited cell proliferation $(\mathrm{P}<0.05)$, while interference with the expression of miR-211-5p reversed the above effects $(\mathrm{P}<0.05)$ (Figure 2B). Cell transfection with the miR-211-5p mimic increased Caspase- 3 activity $(\mathrm{P}<0.05)$, and markedly increased the cell apoptosis rate $(\mathrm{P}<0.05)$ (Figures $2 C, D)$. Also, after transfection of the miR-211-5p mimic inhibitor, the Caspase- 3 activity and apoptosis rate of cells were notably reduced (both $\mathrm{P}<0.05$ ) (Figure $2 C, D$ ). Furthermore, miR-211-5p significantly inhibited the migration and invasion of hHSFs (both $\mathrm{P}<0.05$ ) (Figure $2 E, F$ ). It is known that CCND1, C-myc, Bax, Bcl-2, MMP3, and MMP9 are important biological markers of cell proliferation, apoptosis, migration, and invasion, respectively. In this study, the expression levels of these proteins in cells were 
A

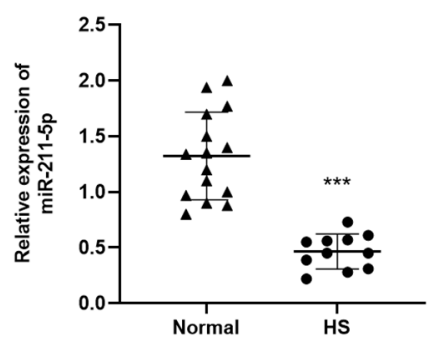

C

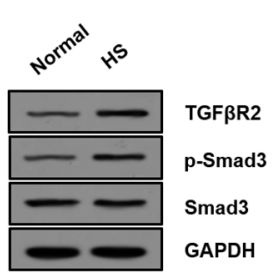

B
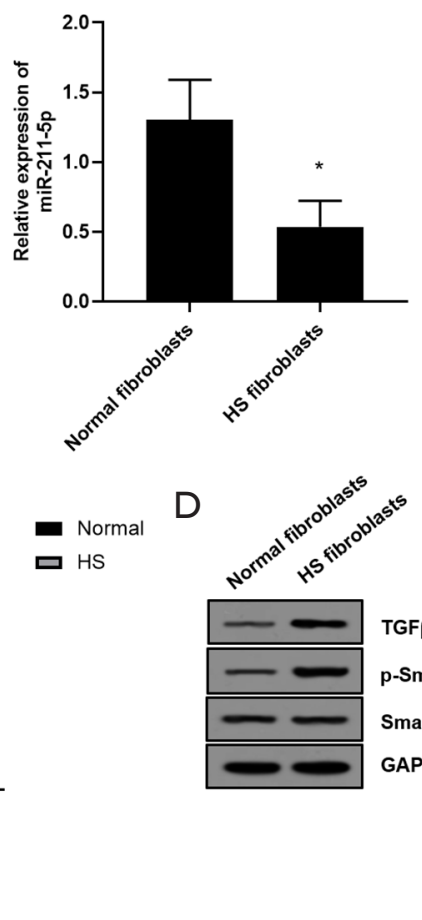
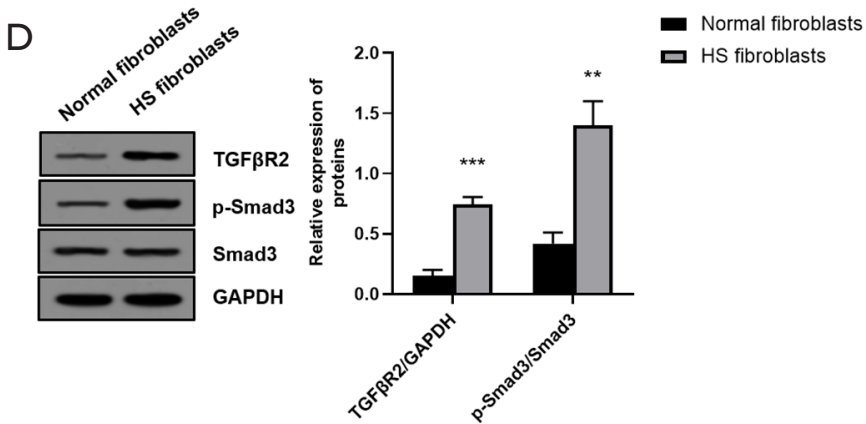

Figure 1 The level of miR-211-5p in HS tissues and hHSFs was decreased and the TGFßR2/Smad3 pathway was activated in HS tissues and HS fibroblasts. (A) The relative levels of miR-211-5p in HS tissues $(\mathrm{n}=15)$ and normal control tissues (normal, $\mathrm{n}=15)$ were determined by qRT-PCR. ***, $\mathrm{P}<0.001$ vs. normal group; (B) the relative quantification of miR-211-5p in hHSFs and normal fibroblasts (n=3) were determined by qRT-PCR. *, $\mathrm{P}<0.05$ vs. normal fibroblasts. (C) Western blot detection of TGF $\beta$ R2, Smad3 and p-Smad3 protein expression levels in HS tissues ( $\mathrm{n}=15)$ and normal control tissues (normal, $\mathrm{n}=15)$. ** $\mathrm{P}<0.01$ vs. normal group; (D) Western blot detection of TGF $3 \mathrm{R} 2$, Smad3 and p-Smad3 protein expression levels in HS tissue and normal tissue fibroblasts. ${ }^{* *}, \mathrm{P}<0.01$. ***, $\mathrm{P}<0.001$ vs. normal fibroblasts. HS, hypertrophic scar; hHSFs, human hypertrophic scar fibroblasts.

measured by western blot. As shown in Figure $2 G$, when the cells overexpressed miR-211-5p, the expression levels of CCND1, C-myc, Bcl-2, MMP3, and MMP9 were markedly reduced (all $\mathrm{P}<0.05$ ), while the Bax level increased notably (all $\mathrm{P}<0.05$ ). However, interference with miR211-5p reversed the expression level changes of the abovementioned proteins (all $\mathrm{P}<0.05$ ).

\section{miR-211-5p inbibited collagen deposition and activation of the TGF-BR2/Smad3 signaling pathway}

As shown in Figure 3A, we found that, compared with the control group, the protein levels of $\alpha$-SMA, Col I, and Col III in hHSFs transfected with the miR-211-5p mimic were significantly down-regulated (all $\mathrm{P}<0.05$ ), while cells transfected with the miR-211-5p inhibitor were markedly up-regulated (all $\mathrm{P}<0.05$ ). We also determined the activation of the TGF- $\beta$ R $2 / S \operatorname{Smad} 3$ signaling pathway, which plays an important role in the occurrence and development of HS. As shown in Figure 3B, when the cells overexpressed miR$211-5 \mathrm{p}$, the activation of the TGF- $\beta$ R $2 / \mathrm{Smad} 3$ pathway was inhibited $(\mathrm{P}<0.05)$. Conversely, when the level of miR$211-5 p$ in cells was decreased, the pathway was activated $(\mathrm{P}<0.05)$.

\section{TGFBR2 is the target of miR-211-5p}

To explore the potential role of miR-211-5p, the target of miR-211-5p was predicted through TargetScan bioinformatics analysis. As shown in Figure $4 A$, it was predicted that the 3 '-UTR of TGF $\beta$ R2 contained the predicted target site for miR-211-5p. To verify whether miR-211-5p could directly target the 3'-UTR of TGFßR2, we used the 3 '-UTR reporter vector of TGF $\beta R 2$ to conduct the dual-luciferase analysis. We found that the overexpression of miR-211-5p significantly reduced the 
A

D
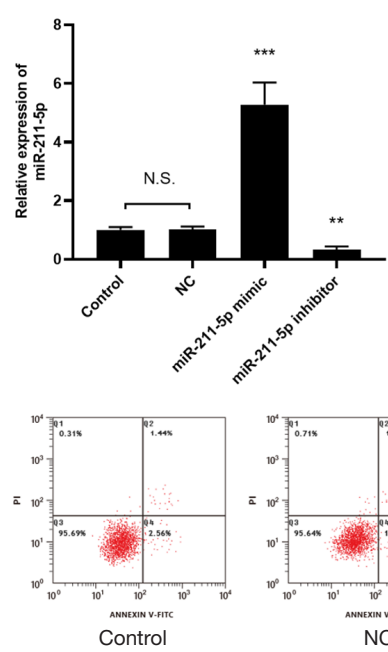

$E$

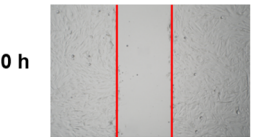

$48 \mathrm{~h}$

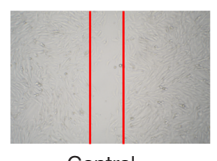

$\mathrm{F}$
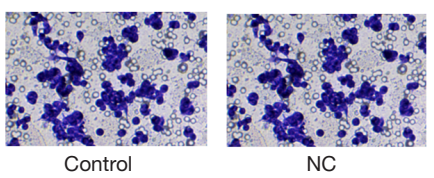

B
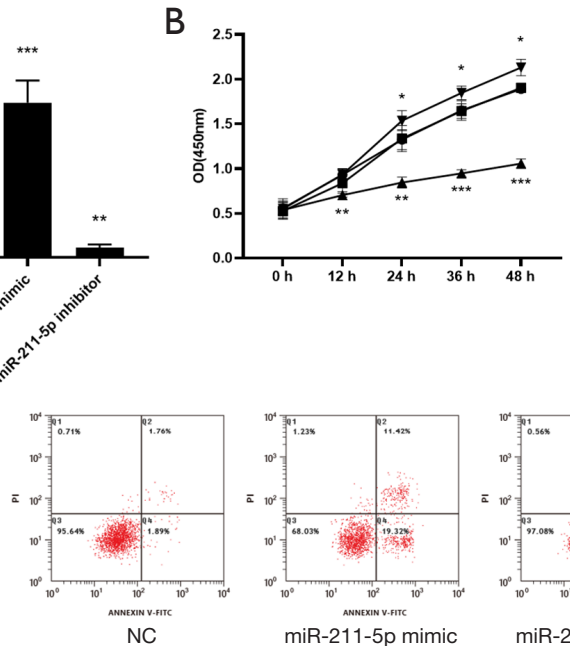

NC

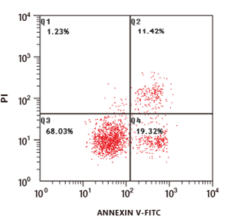

miR-211-5p mimic
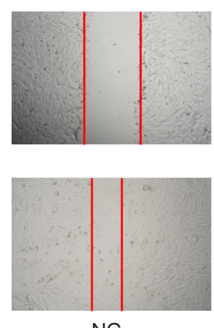

NC
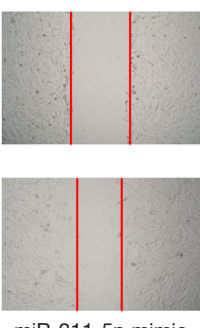

miR-211-5p mimic

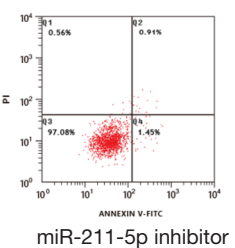

- Control

- NC

\pm miR-211-5p mimic

- miR-211-5p inhibito
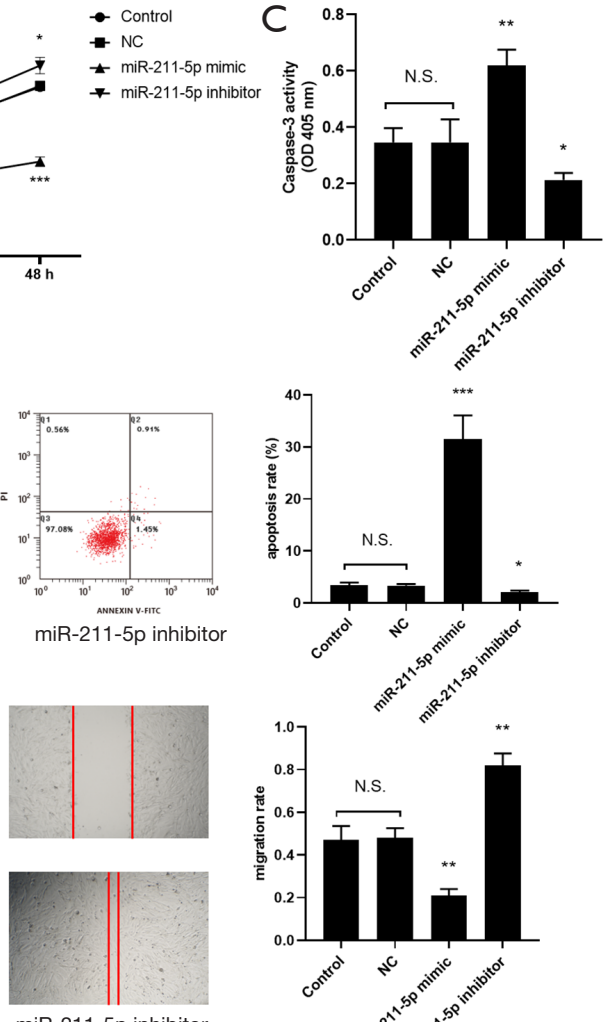

miR-211-5p inhibitor
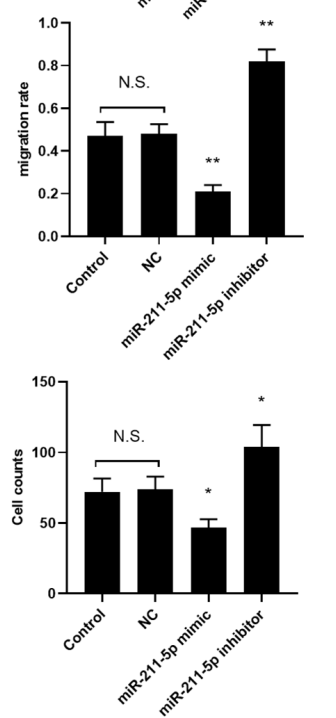

G
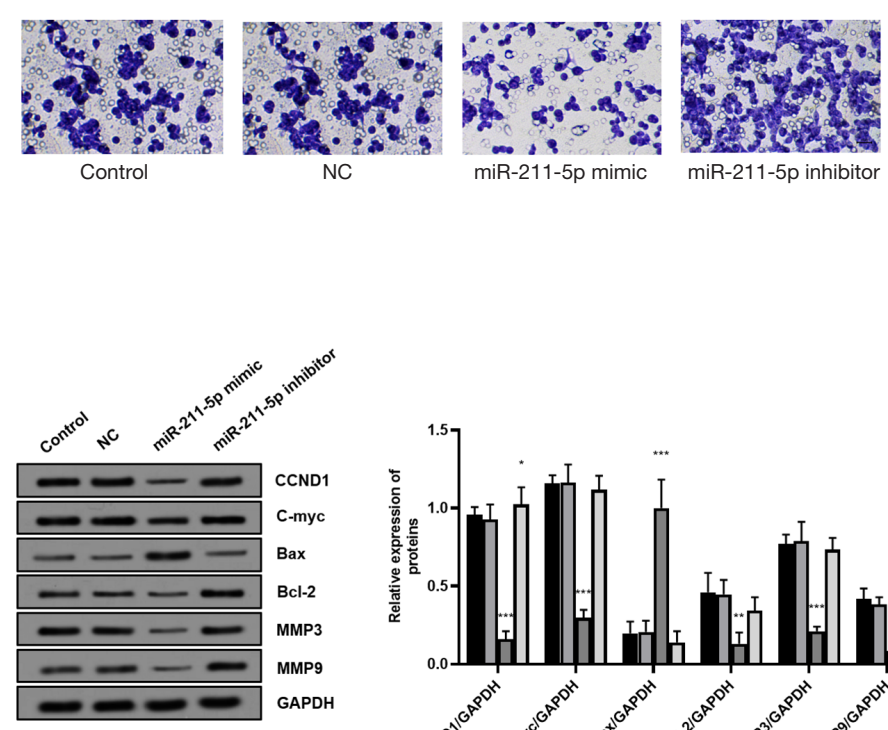

- Contro

口 NC

口 miR-211-5p mimic

口 miR-211-5p inhibitor

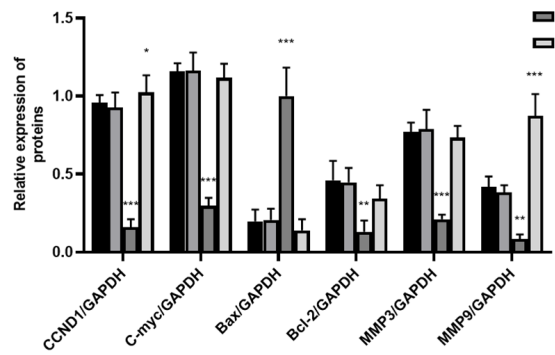

Figure 2 miR-211-5p inhibits the functions of hHSFs, and induces their apoptosis. (A) The effectiveness of the miR-211-5p mimic and inhibitor were verified by qRT-PCR; (B) the CCK-8 method was used to detect cell proliferation after transfection of the miR-211-5p mimic and inhibitor; (C) measurement of cell Caspase-3 activity; (D) changes in the cell apoptosis rate were detected by flow cytometry; (E) the scratch test was used to measure cell migration; magnification, 40x; (F) the cell invasion test was used to evaluate cell invasion; cells were stained with $0.5 \%$ crystal violet solution; magnification, $100 \times$; $(\mathrm{G})$ western blotting was used to determine the expression levels of proliferation-, migration-, invasion-, and apoptosis-related proteins in cells. $\mathrm{n}=3$. N.S., $\mathrm{P}>0.05$; ${ }^{*}, \mathrm{P}<0.05 ;{ }^{* *}, \mathrm{P}<0.01$; ${ }^{* * *}, \mathrm{P}<0.001$ vs. Control group. hHSFs, human hypertrophic scar fibroblasts; CCK-8, cell counting kit-8. 
A
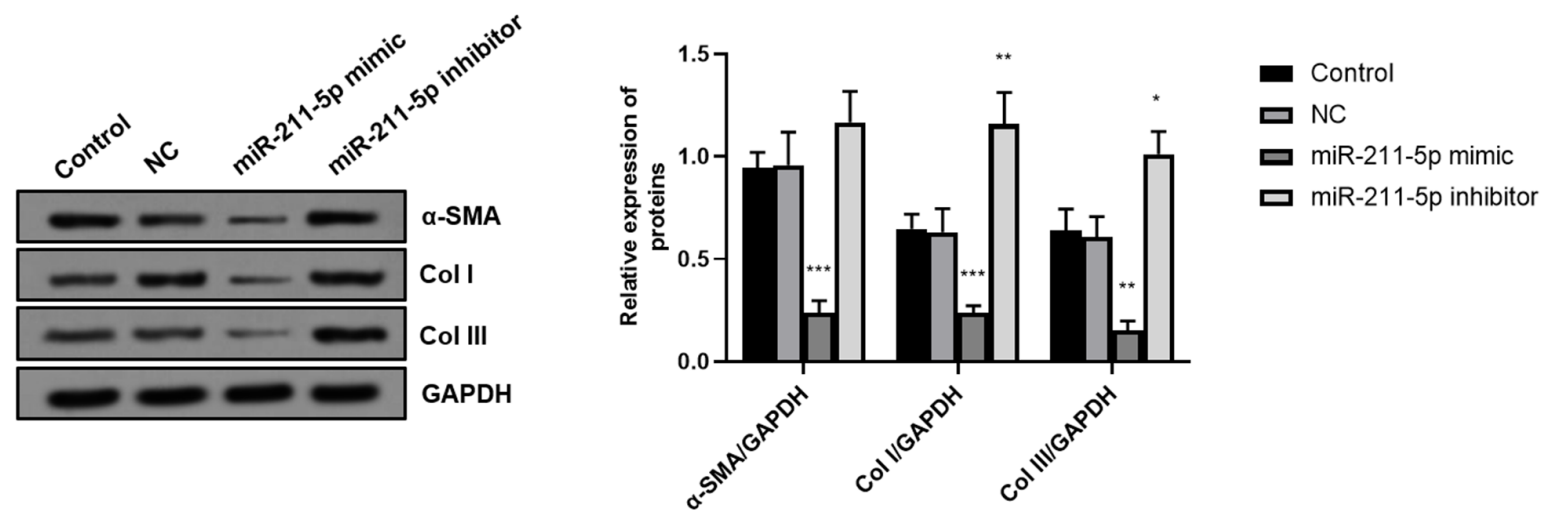

B
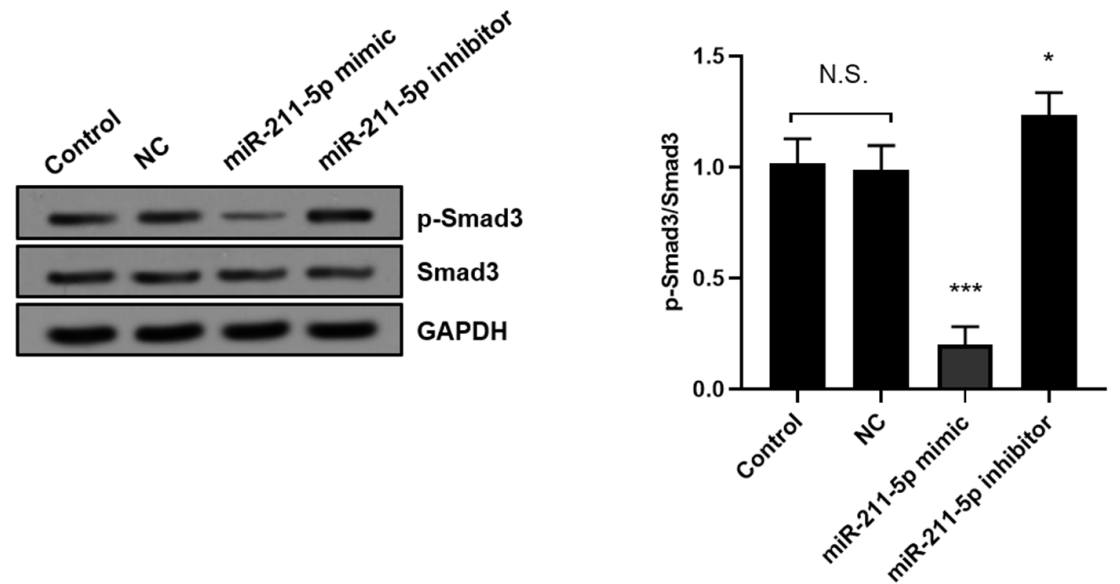

Figure 3 miR-211-5p inhibited collagen deposition and the activation of the TGF $\beta$ R2/Smad3 signaling pathway. (A) Western blot was used to determine the protein expression levels of ECM marker proteins including $\alpha$-SMA, Col I, and Col III; (B) Western blot was used to measure the phosphorylation level of smad3. N.S., $\mathrm{P}>0.05 ;{ }^{*}, \mathrm{P}<0.05$; ${ }^{* *}, \mathrm{P}<0.01$; ${ }^{* * *}, \mathrm{P}<0.001$ vs. Control group. ECM, extracellular matrix.

luciferase activity of the WT TGFßR2 3'-UTR reporter vector $(\mathrm{P}<0.05)$, while there was no notable effect on the luciferase activity of the TGF $\beta$ R2 3'-UTR reporter vector containing the miR-211-5p mutation binding site $(\mathrm{P}>0.05)$ (Figure $4 B)$. To further confirm that TGF $\beta \mathrm{R} 2$ is the target gene of miR-211-5p, the effect of miR-211-5p on the expression of TGF $\beta R 2$ was examined. As shown in Figure $4 C$, the overexpression of miR-211-5p markedly reduced the protein expression level of TGF $\beta R 2(\mathrm{P}<0.05)$, while the inhibition of miR-211-5p expression had the opposite effect $(\mathrm{P}<0.05)$.

\section{miR-211-5p reversed the effects of TGFßR2 on $H S$ fibroblasts}

We also verified the effectiveness of the TGF $\beta$ R2 overexpression plasmid (all $\mathrm{P}<0.05$ ) (Figure $5 A, B$ ). Subsequently, the CCK- 8 method was used to measure the effects of co-transfection of miR-211-5p and TGF $\beta$ R2 on cell proliferation. The overexpression of TGF $\beta$ R2 significantly promoted $\mathrm{hHSF}$ s proliferation $(\mathrm{P}<0.05)$, and when miR-211-5p was overexpressed at the same time, the proliferation activity was reversed $(\mathrm{P}<0.05)$ (Figure 5C). In terms of apoptosis, the overexpression of miR-211-5p reversed the apoptosis-inhibiting effect of TGF $\beta$ R2 overexpression (all $\mathrm{P}<0.05$ ) (Figure $5 D, E)$. In terms of cell migration and invasion, the overexpression of miR-211-5p in hHSFs cells reversed the enhancement of migration and invasion caused by the overexpression of TGF $\beta R 2$ (both $\mathrm{P}<0.05$ ) (Figure $5 F, G)$. Furthermore, we also measured the expression of cell function-related proteins by western blot. As shown in Figure 5H, the overexpression of miR- 
A

WT-TGFBR2-3'-UTR: 5'... ACUACUAUACAUAAAGGGAAAG... || ||| || hsa-miR-211-5p: 3'...CGCUUCCUACUGUUUCCCUU

MUT-TGFBR2-3'-UTR: 5'...ACUACUAUACAUAUCCUUGUAG...

C
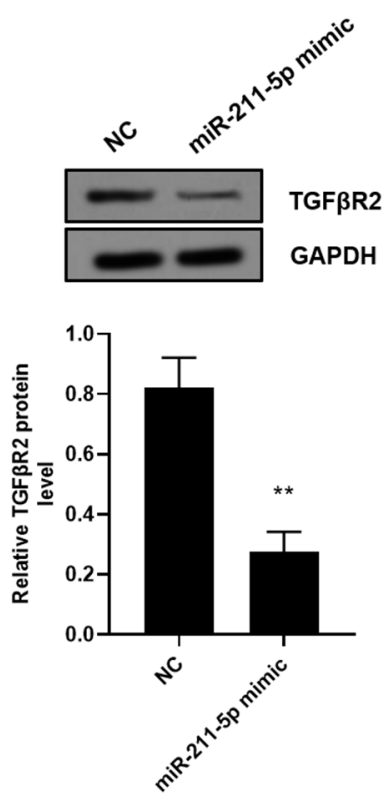

B

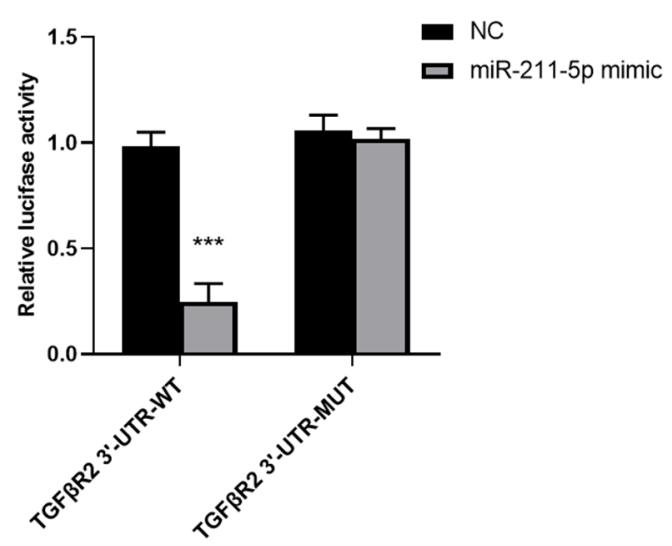

Figure 4 TGFßR2 is the target of miR-211-5p. (A) Prediction of the binding site between the 3'-UTR of TGFßR2 and miR-211-5p; (B) detection of luciferase activity of the reporter gene transfected either with TGFßR2 3'-UTR-WT or TGFßR2 3'-UTR-MUT binding site. $\mathrm{NC}$ was used as the control, and the difference in luciferase activity after transfection of the miR-211-5p mimic was measured; (C) Western blot was used to measure the levels of TGF $\beta$ R2 protein in cells transfected with NC, miR-211-5p mimic or inhibitor, or miR-NC. *, $\mathrm{P}<0.05$; ${ }^{* *}, \mathrm{P}<0.01 ;{ }^{* * *}, \mathrm{P}<0.001$ vs. NC group.

211-5p reversed the changes in the expression levels of CCND1, C-myc, Bax, Bcl-2, MMP3, and MMP9 caused by the overexpression of TGF 3 R2 (all $\mathrm{P}<0.05$ ). The above results suggest that miR-211-5p can reverse the regulation of TGF $\beta 22$ on the proliferation, migration, invasion, and apoptosis of hHSFs.

\section{miR-211-5p reversed TGFBR2's promotion of collagen deposition and the activation of the TGFBR2/Smad3 signaling patbway}

As shown in Figure 6A, transfection with the miR-211-5p mimic reversed the changes in the protein levels of $\alpha$-SMA, $\mathrm{Col}$ I, and Col III in hHSFs caused by the overexpression of TGF $\beta$ R2 (all $\mathrm{P}<0.05)$. The activation of the TGF $\beta$ R2/ Smad3 pathway caused by TGF $\beta$ R2 was also suppressed by the overexpression of miR-211-5p $(\mathrm{P}<0.05)$, as shown in Figure $6 B$.

\section{Discussion}

The present study found that the expression of miR-211-5p was decreased in HS tissues and hHSFs cells, and that inhibited hHSF proliferation, migration, and invasion by inhibiting the expression of TGF $\beta$ R2. MiR-211-5p also induced the occurrence of apoptotic responses, reduced the accumulation of ECM, and inhibited the activation of TGF- $\beta$ R2/Smad3 pathway. The above results indicate that 
A
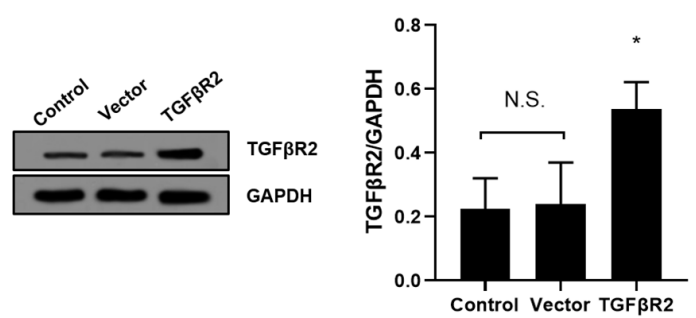

C

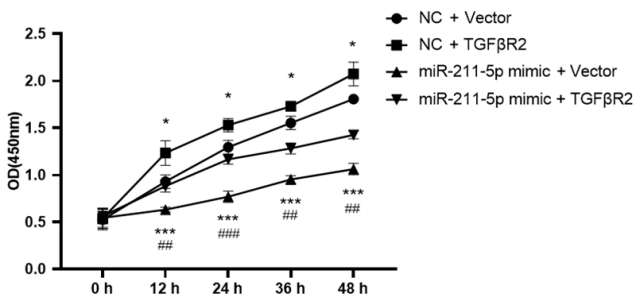

E

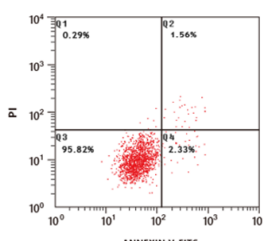

$\mathrm{NC}+$ Vector

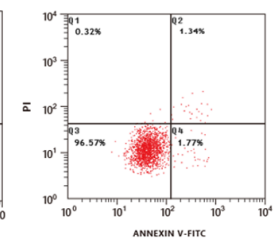

$\mathrm{NC}+\mathrm{TGF} \beta \mathrm{R} 2$

$\mathrm{F}$

$\mathbf{O h}$

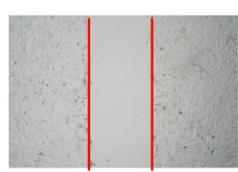

$48 \mathrm{~h}$

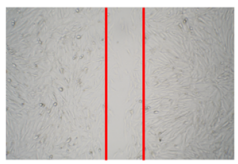

$\mathrm{NC}+$ Vector
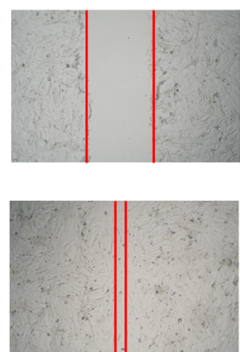

$\mathrm{NC}+\mathrm{TGF} \beta \mathrm{R} 2$
B

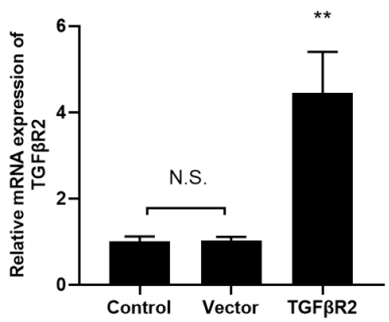

D

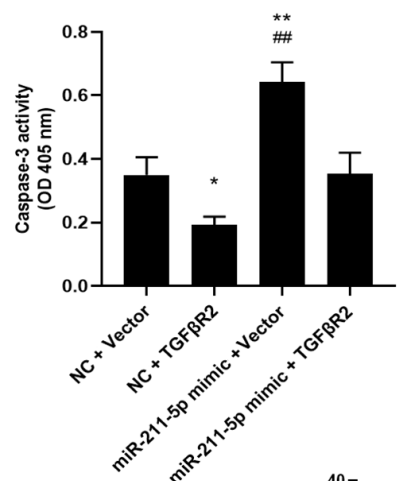

G
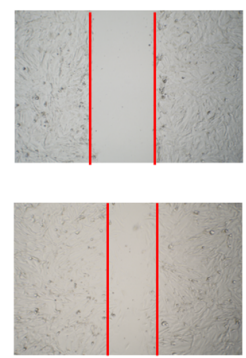

miR-211-5p mimic + Vector

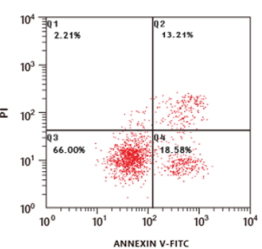

miR-211-5p mimic + Vector

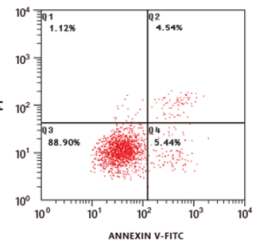

miR-211-5p mimic + TGFßR2
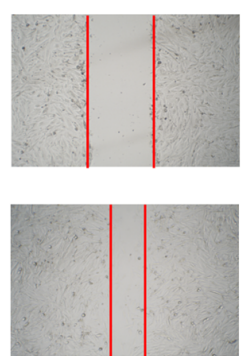

miR-211-5p mimic + TGF $\beta R 2$

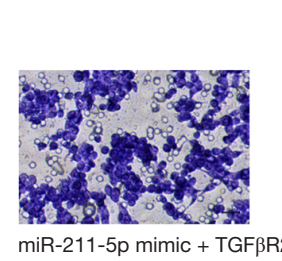

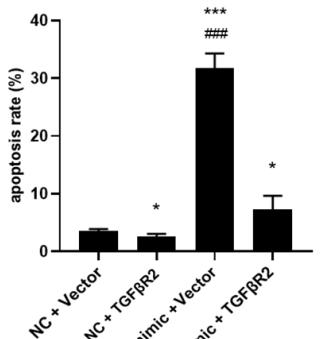

مी
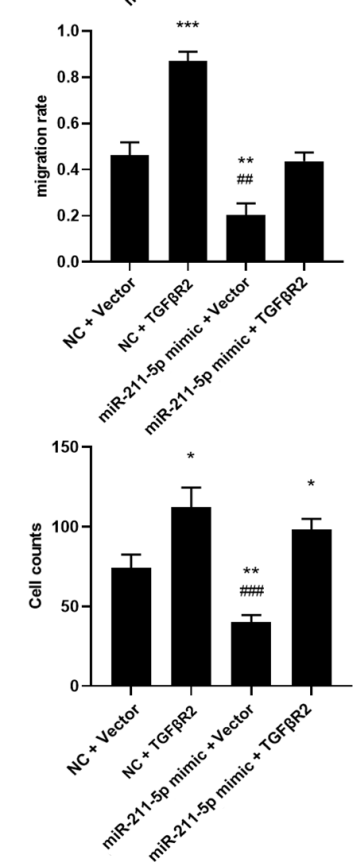

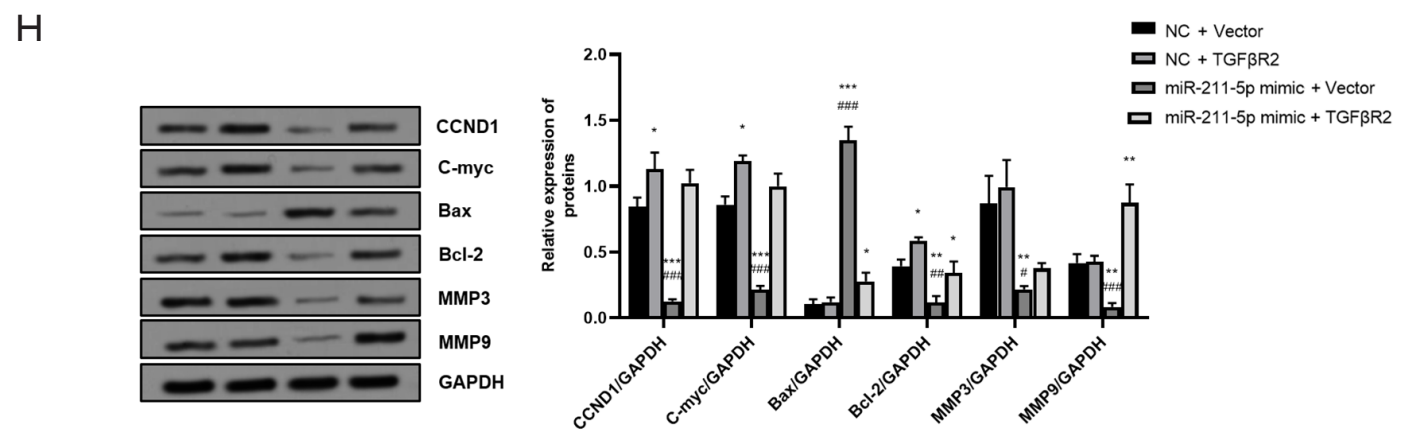

Figure 5 miR-211-5p reversed the effects of TGF $\beta$ R2 overexpression on HS fibroblasts. (A,B) The effectiveness of cells transfected with the TGFßR2 overexpression plasmid was verified by qRT-PCR and western blot; (C) cell proliferation after transfection with the empty plasmid (Vector) and TGF $\beta$ R2 overexpression plasmid was measured using the CCK-8 method; (D) measurement of cell Caspase-3 activity; (E) changes in cell apoptosis rate were determined by flow cytometry; (F) the scratch test was performed to measure cell migration; magnification, 40×; $(\mathrm{G})$ the cell invasion test was used to evaluate cell invasion; cells were stained with $0.5 \%$ crystal violet solution; magnification, 100×; $(\mathrm{H})$ Western blot was used to determine the levels of proliferation-, migration-, invasion-, and apoptosis-related proteins in cells. $\mathrm{n}=3$. N.S., $\mathrm{P}>0.05 ;{ }^{*}, \mathrm{P}<0.05 ;{ }^{* *}, \mathrm{P}<0.01 ;{ }^{* *}, \mathrm{P}<0.001$ vs. Control group; ${ }^{*}, \mathrm{P}<0.05 ;{ }^{* \#}, \mathrm{P}<0.01 ;{ }^{\# \#}, \mathrm{P}<0.001$ vs. miR-211-5p + TGFßR2 group. CCK-8, cell counting kit-8.

the miR-211-5p/TGF $\beta$ R2 axis may be a potential target for the treatment of HS.

The healing process of normal and pathological wounds is complex $(21,22)$. Histologically, HS is characterized by excessive proliferation of fibroblasts and mast cells, accompanied by excessive accumulation of ECM (23). However, the exact pathogenesis of HS is still unclear, and the current treatment methods are also limited (5). In recent years, studies have found that abnormal miRNA expression plays a key role in the progression of skin fibrosis (24). Previous studies have demonstrated the anti-cancer or tumor-promoting effects of miR-211-5p in various tumors. For example, miR-211-5p can promote cancer cell survival by inhibiting the circadian rhythm regulators and protein synthesis (25). MiR-211-5p may also be able to enhance the proliferation, colony formation, and invasion of nonsmall cell lung cancer (NSCLC) cells by targeting sarcoma (SRC) kinase signaling inhibitor 1 (26). However, in cervical cancer, miR-211-5p can inhibit the proliferation, invasion, and migration of cancer cells by targeting secreted protein acidic and rich in cysteine (SPARC) (27). Furthermore, miR-211-5p has been shown to promote the sensitivity of platinum drugs by blocking the DNA damage response in ovarian cancer (28). Finally, in ischemia/reperfusion kidney injury, Shang et al. found that TGF 3 R2 is the target gene of miR-211-5p, where it can reduce cell apoptosis and injury by inhibiting TGF- $\beta$ R2/Smad3 signal activation (20). However, there are no relevant reports on the role of $\mathrm{miR}-211-5 \mathrm{p}$ in
HS. Therefore, this study first measured the levels of miR211-5p in HS tissues and hHSFs cells and subsequently explored its biological effects.

By measuring the level of miR-211-5p in HS tissues and hHSFs cells, we discovered that the level of miR-211-5p was significantly down-regulated, and the TGF 3 R2/ Smad3 signaling pathway was activated. By overexpressing and inhibiting the expression level of miR-211-5p in hHSFs cells, miR-211-5p had the effects of inhibiting fibroblast proliferation, invasion, and migration, and inducing fibroblast apoptosis. It is known that CCND1 and $\mathrm{C}$-myc are important factors that regulate the cell cycle and cell proliferation (29). Furthermore, Bax and Bcl-2 are key proteins that promote apoptosis and antiapoptosis, respectively (30). Also, MMP3 and MMP9, which can regulate the synthesis and degradation of ECM at the wound site, are protein factors that can regulate cell migration and invasion (31). In this study, the expression levels of the above-mentioned proteins in the cells were measured by western blot, and it was found that their expression levels were consistent with the results of cell function. That is, the expression levels of proliferationpromoting proteins including CCND1 and C-myc, the pro-invasion and migration-promoting proteins including MMP3 and MMP9, and the anti-apoptosis protein, Bcl-2, were decreased, while the expression of the pro-apoptotic protein, Bax, was up-regulated. Furthermore, we also measured the expression levels of ECM marker proteins 
A
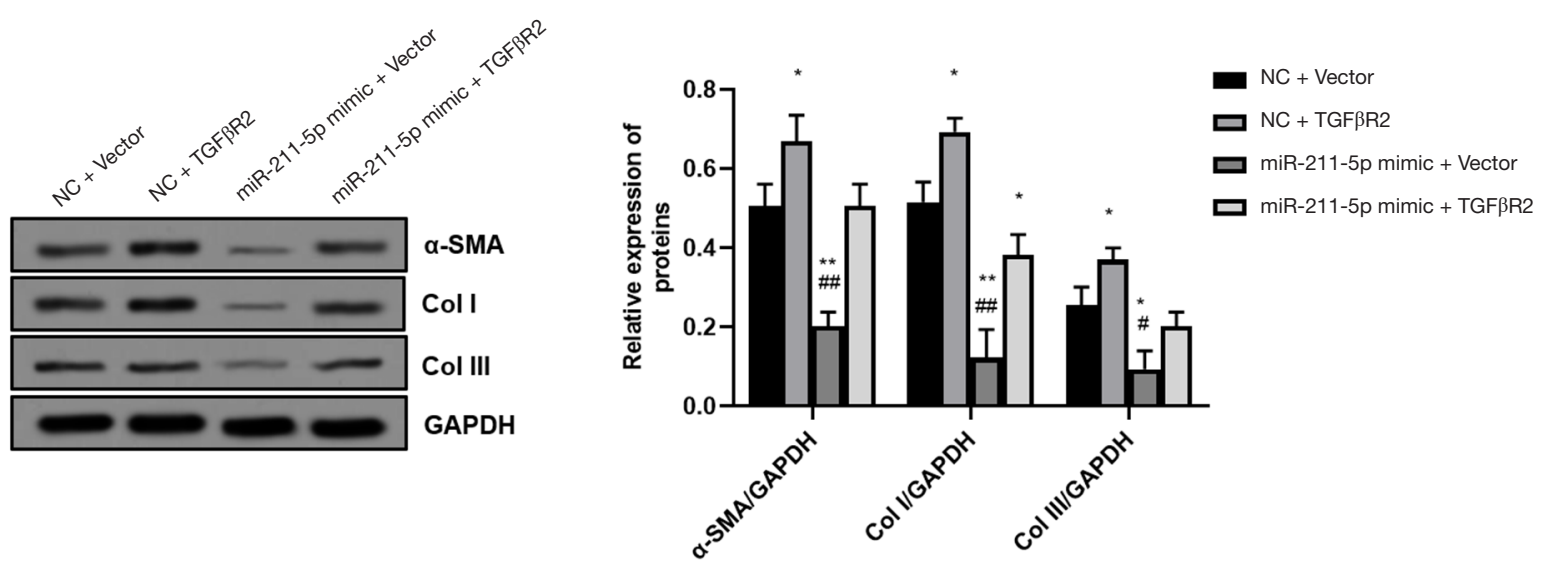

B
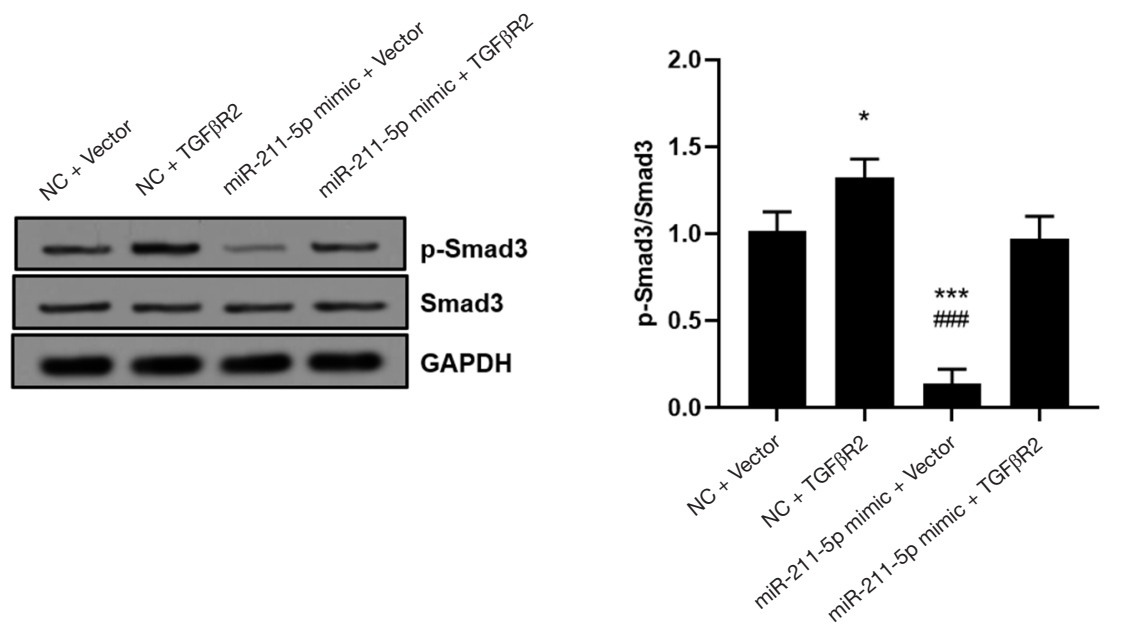

Figure 6 miR-211-5p reversed TGF $\beta$ R2's promotion of collagen deposition and the activation of the TGF $\beta /$ Smad3 signaling pathway. (A) Western blot was used to determine the protein expression levels of ECM marker proteins including $\alpha$-SMA, Col I, and Col III; (B) Western blot was performed to measure the phosphorylation level of smad3. N.S., $\mathrm{P}>0.05 ;{ }^{*}, \mathrm{P}<0.05 ;$ **, $\mathrm{P}<0.01$; ***, $\mathrm{P}<0.001$ vs. Control group. *, $\mathrm{P}<0.05 ;{ }^{\# \#}, \mathrm{P}<0.01 ;{ }^{\# \# \#}, \mathrm{P}<0.001$ vs. $\mathrm{NC}+\mathrm{TGF} \beta \mathrm{R} 2$ group.

including $\alpha$-SMA, Col I, and Col III, and found that miR211-5p could suppress ECM accumulation. MiR-211-5p may exert the above-mentioned effects by inhibiting the activation of the TGF- $\beta$ R $2 / \operatorname{Smad} 3$ signaling pathway.

Shang et al. found that miR-211-5p could target TGFßR2 (20). We predicted the possible binding site between miR-211-5p and the 3'-UTR of TGF $\beta R 2$ through bioinformatic analysis, and found that the up-regulation of miR-211-5p in hHSFs significantly inhibited the luciferase activity of TGF $\beta$ R2 with the 3'-UTR-WT, which is consistent with previous studies. It is known that TGF $\beta$ R2 is a transmembrane receptor of the TGF $\beta /$ Smad signaling pathway, which can induce phosphorylation of Smad2/3 and inhibit cell apoptosis (32). TGF- $\beta$ can also initiate and terminate tissue repair, and its continued production will promote the development of fibrosis (33). Moreover, it has been established that TGF- $\beta$ is involved in various fibrous diseases, which can affect the functions of many organs (34). TGF- $\beta$ plays a role by binding to TGF $\beta R 2$. Recently, it was shown that TGF- $\beta$ R2/Smad signaling plays an important role in the formation of normal and HSs (35). Also, Smad3, as a member of the Smad family, can mediate the production of collagen by dermal fibroblasts stimulated by TGF- $\beta$ (35). Liu et al. found that blocking the TGF- $\beta$ R2/Smad signaling pathway could prevent the formation of HS (36). To verify these findings, we demonstrated that the up-regulation of miR-211-5p inhibited the levels of TGF $\beta R 2$ protein, while suppressing the expression of miR-211-5p increased the TGFßR2 protein expression level, thereby further verifying the target relationship between miR-211-5p and TGFßR2. 
Subsequently, hHSFs cells were co-transfected with a miR-211-5p mimic and a TGF $\beta$ R2 overexpression plasmid to observe the reversal effect of miR-211-5p on TGF $\beta R 2$. Specifically, the overexpression of TGF $\beta$ R2 enhanced cell proliferation, invasion, and migration, while apoptosis was inhibited, ECM production was reduced, and the TGF$\beta R 2 / S m a d 3$ signaling pathway was activated. On the other hand, when miR-211-5p was co-transfected, the above effects were reversed, suggesting that the overexpression of miR-211-5p can eliminate the effects of TGF $\beta 22$.

In summary, this study found, for the first time, that miR-211-5p could deactivate the TGF- $\beta$ R2/Smad3 signaling pathway by targeting TGF $\beta$ R2, regulate cell proliferation, invasion, migration, apoptosis, and genes related to ECM collagen production. It could also inhibit hHSF proliferation, invasion, migration, and promote its apoptosis. Therefore, miR-211-5p is expected to become a potential target for the treatment of HS.

\section{Acknowledgments}

Funding: This research is supported by the key research and development project of Sichuan Province Science and Technology Plan (2020YFS0267).

\section{Footnote}

Reporting Checklist: The authors have completed the MDAR reporting checklist. Available at http://dx.doi.org/10.21037/ atm-21-1806

Data Sharing Statement: Available at http://dx.doi. org/10.21037/atm-21-1806

Conflicts of Interest: All authors have completed the ICMJE uniform disclosure form (available at http://dx.doi. org/10.21037/atm-21-1806). The authors have no conflicts of interest to declare.

Ethical Statement: The authors are accountable for all aspects of the work in ensuring that questions related to the accuracy or integrity of any part of the work are appropriately investigated and resolved. All procedures performed in this study involving human participants were in accordance with the Declaration of Helsinki (as revised in 2013). The study was approved by the Ethics Committee of West China Hospital, Sichuan University (No.: ChiCTR1800019082) and informed consent was taken from all the patients.

Open Access Statement: This is an Open Access article distributed in accordance with the Creative Commons Attribution-NonCommercial-NoDerivs 4.0 International License (CC BY-NC-ND 4.0), which permits the noncommercial replication and distribution of the article with the strict proviso that no changes or edits are made and the original work is properly cited (including links to both the formal publication through the relevant DOI and the license). See: https://creativecommons.org/licenses/by-nc-nd/4.0/.

\section{References}

1. Rabello FB, Souza CD, Farina Júnior JA. Update on hypertrophic scar treatment. Clinics (Sao Paulo) 2014;69:565-73.

2. Gauglitz GG, Korting HC, Pavicic T, et al. Hypertrophic scarring and keloids: pathomechanisms and current and emerging treatment strategies. Mol Med 2011;17:113-25.

3. Ehrlich HP, Desmoulière A, Diegelmann RF, et al. Morphological and immunochemical differences between keloid and hypertrophic scar. Am J Pathol 1994;145:105-13.

4. Garner WL, Karmiol S, Rodriguez JL, et al. Phenotypic differences in cytokine responsiveness of hypertrophic scar versus normal dermal fibroblasts. J Invest Dermatol 1993;101:875-9.

5. Lee HJ, Jang YJ. Recent Understandings of Biology, Prophylaxis and Treatment Strategies for Hypertrophic Scars and Keloids. Int J Mol Sci 2018;19:711.

6. Bai X, He T, Liu J, et al. Loureirin B inhibits fibroblast proliferation and extracellular matrix deposition in hypertrophic scar via TGF- $\beta /$ Smad pathway. Exp Dermatol 2015;24:355-60.

7. Li G, Zhou R, Zhang Q, et al. Fibroproliferative effect of microRNA-21 in hypertrophic scar derived fibroblasts. Exp Cell Res 2016;345:93-9.

8. Liu B, Liu Y, Wang L, et al. RNA-seq-based analysis of the hypertrophic scarring with and without pressure therapy in a Bama minipig model. Sci Rep 2018;8:11831.

9. Guo B, Hui Q, Xu Z, et al. miR-495 inhibits the growth of fibroblasts in hypertrophic scars. Aging (Albany NY) 2019;11:2898-910.

10. Carthew RW, Sontheimer EJ. Origins and Mechanisms of miRNAs and siRNAs. Cell 2009;136:642-55.

11. Valencia-Sanchez MA, Liu J, Hannon GJ, et al. Control of translation and mRNA degradation by miRNAs and siRNAs. Genes Dev 2006;20:515-24. 
12. Cheng AM, Byrom MW, Shelton J, et al. Antisense inhibition of human miRNAs and indications for an involvement of miRNA in cell growth and apoptosis. Nucleic Acids Res 2005;33:1290-7.

13. Wang R, Bai Z, Wen X, et al. MiR-152-3p regulates cell proliferation, invasion and extracellular matrix expression through by targeting FOXF1 in keloid fibroblasts. Life Sci 2019;234:116779.

14. Zhao F, Lang H, Wang Z, et al. Human Novel MicroRNA Seq-915_x4024 in Keratinocytes Contributes to Skin Regeneration by Suppressing Scar Formation. Mol Ther Nucleic Acids 2019;14:410-23.

15. Li L, Han W, Chen Y, et al. MiR-3613-3p inhibits hypertrophic scar formation by down-regulating arginine and glutamate-rich 1. Mol Cell Biochem 2021;476:1025-36.

16. Chitnis NS, Pytel D, Bobrovnikova-Marjon E, et al. miR-211 is a prosurvival microRNA that regulates chop expression in a PERK-dependent manner. Mol Cell 2012;48:353-64.

17. Ji L, Li X. Long noncoding RNA MEG3 is a tumor suppressor in choriocarcinoma by upregulation of microRNA-211. J Cell Physiol 2019;234:22911-20.

18. Song D, Yang K, Wang W, et al. MicroRNA-211$5 p$ promotes apoptosis and inhibits the migration of osteosarcoma cells by targeting proline-rich protein PRR11. Biochem Cell Biol 2020;98:258-66.

19. Chen LL, Zhang ZJ, Yi ZB, et al. MicroRNA-211-5p suppresses tumour cell proliferation, invasion, migration and metastasis in triple-negative breast cancer by directly targeting SETBP1. Br J Cancer 2017;117:78-88.

20. Shang J, Sun S, Zhang L, et al. miR-211 alleviates ischaemia/reperfusion-induced kidney injury by targeting TGF $\beta$ R2/TGF- $\beta /$ SMAD3 pathway. Bioengineered 2020;11:547-57.

21. Armour A, Scott PG, Tredget EE. Cellular and molecular pathology of HTS: basis for treatment. Wound Repair Regen 2007;15 Suppl 1:S6-17.

22. Schäfer M, Werner S. Transcriptional control of wound repair. Annu Rev Cell Dev Biol 2007;23:69-92.

23. Tredget EE, Nedelec B, Scott PG, et al. Hypertrophic scars, keloids, and contractures. The cellular and molecular basis for therapy. Surg Clin North Am 1997;77:701-30.

24. Babalola O, Mamalis A, Lev-Tov H, et al. The role of microRNAs in skin fibrosis. Arch Dermatol Res 2013;305:763-76.

25. Bu Y, Yoshida A, Chitnis N, et al. A PERK-miR-211 axis suppresses circadian regulators and protein synthesis to promote cancer cell survival. Nat Cell Biol 2018;20:104-15.
26. Ye L, Wang H, Liu B. miR-211 promotes non-small cell lung cancer proliferation by targeting SRCIN1. Tumour Biol 2016;37:1151-7.

27. Qu X, Gao D, Ren Q, et al. miR-211 inhibits proliferation, invasion and migration of cervical cancer via targeting SPARC. Oncol Lett 2018;16:853-60.

28. Wang T, Hao D, Yang S, et al. miR-211 facilitates platinum chemosensitivity by blocking the DNA damage response (DDR) in ovarian cancer. Cell Death Dis 2019;10:495.

29. Ray S, Ju X, Sun H, et al. The IL-6 trans-signalingSTAT3 pathway mediates ECM and cellular proliferation in fibroblasts from hypertrophic scar. J Invest Dermatol 2013;133:1212-20.

30. Zeng J, Jiang B, Xiao X, et al. Inhibition of sphingosine kinase 2 attenuates hypertrophic scar formation via upregulation of Smad7 in human hypertrophic scar fibroblasts. Mol Med Rep 2020;22:2573-82.

31. Wang Q, Dong Y, Geng S, et al. Photodynamic therapy inhibits the formation of hypertrophic scars in rabbit ears by regulating metalloproteinases and tissue inhibitor of metalloproteinase-1. Clin Exp Dermatol 2014;39:196-201.

32. Goumans MJ, Valdimarsdottir G, Itoh S, et al. Balancing the activation state of the endothelium via two distinct TGF-beta type I receptors. EMBO J 2002;21:1743-53.

33. Nong X, Rajbanshi G, Chen L, et al. Effect of artesunate and relation with TGF- $\beta 1$ and SMAD3 signaling on experimental hypertrophic scar model in rabbit ear. Arch Dermatol Res 2019;311:761-72.

34. Liu Y, Huang G, Mo B, et al. Artesunate ameliorates lung fibrosis via inhibiting the Notch signaling pathway. Exp Ther Med 2017;14:561-6.

35. Zhang YF, Zhou SZ, Cheng XY, et al. Baicalein attenuates hypertrophic scar formation via inhibition of the transforming growth factor- $\beta / \mathrm{Smad} 2 / 3$ signalling pathway. Br J Dermatol 2016;174:120-30.

36. Liu J, Zhao B, Zhu H, et al. Wnt4 negatively regulates the TGF- $\beta 1$-induced human dermal fibroblast-tomyofibroblast transition via targeting Smad3 and ERK. Cell Tissue Res 2020;379:537-48.

(English Language Editor: A. Kassem)

Cite this article as: Tang J, Yang J, Hu H, Cen Y, Chen J. miR-211-5p inhibits the proliferation, migration, invasion, and induces apoptosis of human hypertrophic scar fibroblasts by regulating TGFßR2 expression. Ann Transl Med 2021;9(10):864 doi: 10.21037/atm-21-1806 